\title{
Miscellany
}

\section{Alois Alzheimer Award}

Novartis Pharma, Germany, sponsors the Alois Alzheimer Award for outstanding achievements in the research of Alzheimer's disease and/or other neurodegenerative disorders. The research of the future award winner should have led to new insights into the aetiology, pathogenesis, diagnosis or treatment of Alzheimer's disease. The Alois Alzheimer Award is endowed with US\$20000. Applications or proposals for nomination, which should include a short curriculum vitae and reprints of up to three relevant papers, should be directed to the Secretary of the Jury Board, as follows: Professor Dr H. J. Möller, Chairman of the University Hospital of Psychiatry, Nussbaumstraße 7, 80336 Munich, Germany. The deadline for applications/ nominations is 15 October 1999 .

\section{New CME Library Audio Tapes}

A review of New CME Library Audio Tapes: Alcoholism, Addiction and Substance Abuse (S. Blume, M. Gold, O'Malley, et al (1997) London: Eurospan Scientific, Technical and Medical Group. £99.50) was published in the June issue of Psychiatric Bulletin. Some readers have subsequently had problems obtaining these library audio tapes through Eurospan in the UK
Eurospan have recommended that requests be made to Marsha Nolfi, American Psychiatric Publishing Group, $1400 \mathrm{~K}$ Street NW, Washington, DC 2005, USA (telephone: 001226826268 ; fax: 001202789 2645).

\section{New Publication}

The Mind and Its Discontents, An Essay in Discursive Psychiatry, by Grant Gillett, Professor of Biomedical Ethics, University of Otago, is a new title from Oxford University Press. This book explores the links between mind, brain, and mental disorder, and brings together insights from psychiatry, philosophy of mind, psychology and medical ethics. The author uses material arising in the study of philosophy of mind, epistemology, post-modern continental philosophy, and philosophy of language to try to elucidate the nature of psychiatric phenomena. Within this framework, a series of chapters analyse psychiatric disorders such as depression, attention deficiency, autism, schizophrenia and anorexia. Gillett also explores the nature of memory and identity; of hysteria and what constitutes rational behaviour; and of what causes some people to label someone a psychopath or deviant. Hardback priced at $£ 50.00$. 